\title{
HISTÓRIA \\ POR UMA HISTÓRIA DAS DIREITAS
}

Fabrício Ferreira de Medeiros

POR UMA HISTÓRIA DAS DIREITAS

\section{FOR A STORY OF THE RIGHTS}

Fabrício Ferreira de Medeiros ${ }^{1}$

\begin{abstract}
RESUMO: Alguns estudos indicaram o surgimento de "novas direitas" junto às redemocratizações latino-americanas da década de 1980. Ademais, a atual conjuntura de crise permitiu que as noções de direita e esquerda retomassem o debate público. Assim, por meio de uma revisão bibliográfica, busco identificar interpretações sobre esta temática e avaliar a operacionalidade analítica do conceito de direita. Argumento que as direitas são plurais ao nível ideológico e de atuação. Por fim, defendo que o estudo sobre as direitas é fundamental na explicação dos processos políticos observados no Brasil recente (pós-1985), especialmente no que tange ao combate às desigualdades socioeconômicas e a questões que atritam com valores cristãos conservadores, como o aborto e a diversidade de gênero.
\end{abstract}

Palavras-chave: Direitas; Interpretações; Processos políticos.

ABSTRACT: Some studies have indicated the emergence of "new rights" alongside Latin American re-democratizations of the 1980s. In addition, the current crisis situation has allowed the notions of right and left to return to public debate. Thus, through a bibliographical review, I seek to identify interpretations on this theme and to evaluate the analytical operability of the concept of the right. I argue that the rights are plural at the ideological and actuarial level. Finally, I argue that the study of rights is fundamental in explaining the political processes observed in recent Brazil (post-1985), especially in the fight against socioeconomic inequalities and issues that clash with conservative Christian values, such as abortion and the diversity of gender.

Keywords: Right; Interpretations; Political processes.

Introdução

O debate político brasileiro experimenta, atualmente, uma multiplicação dos usos dos termos esquerda e direita. Porém, em vários casos, trata-se de uma forma

\footnotetext{
${ }^{1}$ Mestrando pelo Programa de Pós-Graduação em História da Universidade do Estado do Rio de Janeiro (PPGHUERJ) e pelo Programa de Pós-Graduação em Comunicação da Universidade Federal Fluminense (PPGCOM-UFF). Email: fabricio.f.medeiros@hotmail.com
} 


\section{HISTÓRIA \\ POR UMA HISTÓRIA DAS DIREITAS}

Fabrício Ferreira de Medeiros

de criticar e/ou de ofender adversários políticos. O mesmo juízo de valor tem sido frequente em textos acadêmicos, os quais se utilizam daqueles conceitos sem muita objetividade e em tom de acusação. Seja como for, diversos autores têm se debruçado sobre as "novas direitas", buscando interpretar este fenômeno que possui uma dimensão partidária, mas que também abrange setores da sociedade civil. Assim, por meio de uma revisão bibliográfica, busco identificar interpretações sobre esta temática e avaliar a operacionalidade analítica do conceito de direita. Argumento que as direitas são plurais ao nível ideológico (neoliberal, conservadora, nacionalista-ditatorial, neofascista, etc.) e de atuação (via: partidária, midiática, movimentos sociais, religiosa, etc.). Por fim, defendo que o estudo sobre as direitas é fundamental na explicação dos processos políticos observados no Brasil recente (pós-1985), especialmente no que tange ao combate às desigualdades socioeconômicas e a questões que atritam com valores cristãos conservadores, como o aborto e a diversidade de gênero.

As "novas direitas" latino-americanas

O desenvolvimento dos processos de redemocratização na América Latina, na década de 1980, ensejou a produção de diversos textos direcionados a compreender as metamorfoses do espaço político latino-americano e, em especial, o surgimento das chamadas "novas direitas" neste mesmo espaço. Na avaliação de alguns pesquisadores, as "novas direitas" se definem, em boa medida, em relação: ao seu compromisso com o regime democrático, à qualidade da participação política e à possibilidade de ampliação de direitos a segmentos mais extensos da sociedade.

Para Edgar Jiménez (1988), a direita latino-americana se dividia em duas vertentes na década de 1980: uma neoconservadora e uma neoliberal, ambas defensoras de "ideologias de transição" direcionadas a legitimar o controle sobre os movimentos populares em meio às liberalizações políticas do período. Nesta mesma linha de raciocínio, Franz Hinkelammert argumentou que a "nova direita" aceitaria a democracia apenas de modo instrumental à manutenção de seus interesses, defendendo-se a primazia militar na condução daqueles processos político- 


\section{HISTÓRIA \\ POR UMA HISTÓRIA DAS DIREITAS}

Fabrício Ferreira de Medeiros

institucionais, a economia de mercado e a "desvinculación entre democracia y derechos humanos" (HINKELAMMERT, 1988, p. 106).

Buscando compreender as novidades e continuidades presentes na direita latino-americana e brasileira, em particular, Adriano Codato, Bruno Bolognesi e Karolina Roeder (2015) afirmaram que a "nova direita" apresenta elementos característicos da velha direita, a exemplo da defesa do capitalismo como modelo de desenvolvimento e de valores tradicionais (de matriz cristã). Mas, diferentemente do passado, a nova direita aceitaria, pragmaticamente, a promoção de políticas sociais, no intuito de tentar de "se desvincular da memória dos regimes ditatoriais militares apoiados pelos partidos da velha direita" (CODATO; BOLOGNESI; ROEDER, 2015, p. 121). Verónica Giordano (2014), por sua vez, fez considerações semelhantes em relação ao compromisso das direitas com a democracia e as políticas sociais, ressaltando, no entanto, que o elemento central de sua atuação baseava-se no consenso. Para a autora, seria a insistência na defesa de soluções pactuadas ("pelo alto") o traço característico das novas direitas, na medida em que o apelo ao consenso permitiria: 1) na perspectiva da oposição direitista, neutralizar as forças de esquerda, evitando-se sua ascensão eleitoral mediante o questionamento das tensões (desigualdades) políticas e sociais; e 2) na visão da direita governista, "monopolizar los recursos del Estado para construir una democracia aparentemente dialoguista" (GIORDANO, 2014, p. 54), mas assentada na dominação de classe. Atílio Boron (2010) se aproximou da perspectiva de Giornado, ao sugerir que, embora plural, as direitas voltam suas energias para a militarização da política e para a criminalização dos segmentos populares, reagindo contra as transformações sociais e a expansão de direitos.

Aliás, vale observar que uma interpretação semelhante a respeito do comportamento das direitas foi defendida por Leandro Konder, ainda no início da redemocratização, em 1979. Para o filósofo marxista, a direita brasileira, especificamente, teria uma pluralidade ideológica "apenas aparente", se definindo a partir de "uma unidade substancial profunda, inabalável", qual seja, a de que "todas as correntes conservadoras", a despeito de suas crenças e valores, objetivam "impedir que as massas populares se organizem, reivindiquem, façam política e criem uma 


\section{HISTÓRIA \\ POR UMA HISTÓRIA DAS DIREITAS}

Fabrício Ferreira de Medeiros

verdadeira democracia" (KONDER, Unidade da direita, Jornal da República, 20 de set. de 1979, p. 4). Evidenciava-se nesta interpretação a existência de uma direita homogênea em seu sentido político, direcionada à desmobilização popular e à restrição da democracia a seus aspectos jurídico-formais, a exemplo da manutenção de eleições periódicas - garantidas, apenas parcialmente, pelos governos militares pós-1964. De todo modo, a suposta "unidade da direita" não deve ser vista a partir de critérios absolutos, subtraindo-se, analiticamente, a pluralidade ideológica e das formas de atuação das direitas.

Nota-se que um debate muito proveitoso tem sido fomentado no Brasil, na última década, a respeito das direitas, examinadas em âmbitos e com referência a problemáticas distintas. Seja analisando as direitas organizadas em partidos, seja discutindo a atuação política dos evangélicos, investigando grupos militares ou think tanks, ${ }^{2}$ pesquisas estão demonstrando que as direitas apresentam formas variáveis de atuação política, sendo possível, consequentemente, a realização de novos questionamentos. Entretanto, qualquer pesquisador dedicado a esta temática precisa explicitar a própria definição do termo "direita” norteadora de sua pesquisa.

Mas, afinal, o que são as direitas?

Estudar as direitas implica, necessariamente, na exposição dos critérios teóricos que permitem classificar atores, grupos, partidos, movimentos, veículos de comunicação, dentre outras coisas, no campo das direitas. Sem que haja um esforço de teorização, não é possível realizar um trabalho, de fato, acadêmico - não raro, os estudiosos (de ocasião) das direitas têm usado o conceito mais como arma política, de acusação de adversários, do que propriamente como chave analítica de processos políticos.

\footnotetext{
${ }^{2}$ Na definição de Camila Rocha (2015, p. 262), think tanks são "instituições permanentes de pesquisa e análise de políticas públicas que atuam a partir da sociedade civil, procurando informar e influenciar tanto as instâncias governamentais como a opinião pública no que tange à adoção de determinadas políticas públicas". São exemplos de think tanks: a Fundação Getúlio Vargas (FGV), o Instituto Fernando Henrique Cardoso (IFHC), o Instituto Millenium, dentre outros.
} 


\section{HISTÓRIA \\ POR UMA HISTÓRIA DAS DIREITAS}

Fabrício Ferreira de Medeiros

No intuito de definir as direitas, pode ser útil realizar uma leitura cuidadosa dos textos de Jose Romero (1970) e Norberto Bobbio (1995). Para ambos os autores, esquerda e direita são termos relacionais, o que significa dizer que só podem ser compreendidos em relação um ao outro. Trata-se de coordenadas ou subcampos do espaço político nos quais se situam atores com posições distintas em relação a problemas típicos de uma sociedade em dado momento histórico. Segundo Romero (1970), a direita se configura no espaço político em função da análise sobre projetos políticos, ideias, valores e comportamentos concorrentes e/ou antagônicos.

Para Bobbio (1995), por sua vez, a díade anteriormente mencionada e o espaço político se definem em meio às diferenças relativas à concepção de igualdade. $\mathrm{Na}$ avaliação do cientista político, a esquerda se distingue da direita na medida em que assume posicionamentos e projetos igualitários, interpretando como indesejáveis uma série de desigualdades consideradas na condição de construções e produtos sociais; a direita, diferentemente, tenderia a ser inigualitária, ou seja, defenderia a naturalidade da maior parte das desigualdades, logo, vistas como fenômenos que não poderiam ser eliminados.

Assim, argumenta-se que as direitas, no plural, não se definem basicamente em termos ideológicos, mas sim na oposição as esquerdas, em suas mais variadas vertentes (socialista, socialdemocrata, liberal, ambientalista, etc.). Além disso, devese ter em consideração que a classificação de grupos, partidos e movimentos no campo das direitas ou das esquerdas é influenciada pelas posições de quem fala; para um marxista, por exemplo, a esquerda moderada, mais próxima do centro, pode ser vista no campo das direitas, ${ }^{3}$ enquanto que, para um fascista ou um conservador, os neoliberais podem ser tomados como representativos das esquerdas. Em outras palavras, os critérios adotados na classificação de atores inseridos no espaço político

\footnotetext{
${ }^{3}$ Sobre este tipo de abordagem, é interessante conhecer o texto escrito pela filósofa e historiadora Virginia Fontes. A partir de uma leitura marxista, a autora definiu a "nova direita" como sendo "os defensores da grande propriedade", grupo no qual situou: "terratenientes, industriais, comerciantes, banqueiros, acionistas, especuladores, pequenos proprietários de bens correntes, etc" (FONTES, 2010, p. 77), mas também governos. Para Fontes, tanto a defesa quanto a aceitação do estatuto da grande propriedade e do grande capital seriam aspectos indicativos do pertencimento ao campo das direitas, o que, na prática, possibilita classificar enquanto "direita" praticamente qualquer governo, partido ou movimento não adepto do comunismo.
} 


\section{HISTÓRIA \\ POR UMA HISTÓRIA DAS DIREITAS}

Fabrício Ferreira de Medeiros

podem ser melhor compreendidos, dentre outros caminhos, a partir do exame sobre a posição ou identidade política do observador. Ainda assim, é possível adotar um significado para as direitas, assentado razoavelmente em parâmetros gerais e objetivos, menos permeados por paixões políticas.

Para tanto, valho-me da definição defendida por Bobbio (1995), segundo a qual as direitas se comprometem com causas menos igualitárias em comparação às esquerdas. Significa dizer que as direitas veem com naturalidade e inevitabilidade uma série de problemas que, entre as esquerdas, costumam ser interpretados como produtos sociais. Portanto, atento ao contexto brasileiro, considero que o referencial da igualdade é fundamental na análise das direitas, percebido em termos socioeconômicos (renda e educação, por exemplo), mas também ao nível da diferenciação dos gêneros (masculino e feminino) e das orientações sexuais (Lésbicas, Gays, Bissexuais, Travestis, Transexuais e Transgêneros - LGBT). Entendo que a oposição à criação e extensão de programas e políticas distributivas, isto é, ao combate à desigualdade socioeconômica, as posições contrárias à criminalização da homofobia, à descriminalização do aborto e ao reconhecimento da união estável entre pessoas do mesmo sexo são indicadoras da intransigência das direitas no que diz respeito à igualdade de direitos.

Por uma história das direitas: um mapa do caso brasileiro recente

A unidade das direitas em relação ao inigualitarismo e à oposição mais ou menos sistemática às esquerdas não deve nos impedir de perceber a pluralidade de afinidades ideológicas e formas de atuação presentes neste campo. Até porque a diversidade de projetos políticos, valores e ideias pode permitir que ocorram disputas e concorrências entre as direitas. Ademais, o tratamento dispensado pelas direitas no que tange à democracia e às liberdades individuais pode ser nitidamente distinto, com grupos situados na extrema-direita, de viés autoritário e estatista, e grupos situados mais ao centro, portanto, adeptos de posturas e propostas moderadas, relativamente afinadas com a preservação das liberdades individuais e críticas do estatismo. 


\section{HISTÓRIA \\ POR UMA HISTÓRIA DAS DIREITAS}

Fabrício Ferreira de Medeiros

Entre os extremistas de direita, situo tanto os skinheads quanto os nacionalistas-ditatoriais ou autoritários. Os primeiros mereceram um estudo realizado por Jefferson Barbosa recentemente (2016). Nele, o cientista social evidenciou a pluralidade de grupos e facções situadas entre os skinheads, os quais possuem representantes no Brasil, em particular, na cidade de São Paulo. Barbosa mostrou que o movimento skin apropriou-se de ideologias distintas, como o integralismo e o nacional-socialismo, atuando, em alguns casos, com extrema violência, contra "[...] militantes de esquerda, homossexuais, consumidores de entorpecentes e grupos juvenis, tais como roqueiros e punks [...]' (BARBOSA, 2016, p. 85). Por outro lado, é necessário observar que estes grupos não se definem apenas por suas identidades políticas, mas também pela apreciação de determinados valores, tais como: cultura militar, preparo físico, estratégias de confronto, etc. No geral, os skinheads defendem concepções conservadoras relativas a "conduta social, sexual e familiar, com destaque para o repúdio às concepções políticas igualitárias [...]' (BARBOSA, 2016, p. 94).

Entre os nacionalistas-ditatoriais, por seu turno, destaca-se a pesquisa empreendida por Eduardo Santos (2009). Em sua dissertação de mestrado, o pesquisador analisou diversos grupos formados por militares da reserva, da ativa e por civis, os quais tinham por objetivo: "[...] discutir a política do governo em relação ao tratamento dispensado às Forças Armadas, aos salários, e a questões inerentes às prerrogativas militares existentes após o período de redemocratização", assim como elaborar e/ou difundir narrativas alternativas sobre o "[...] regime militar, dentro de uma concepção ideológica nacionalista e antiesquerdista" (SANTOS, 2009, p. 13). Examinando fontes diversas, tais como manifestos, biografias, depoimentos e jornais, o autor demonstrou que diversos grupos enquadrados na extrema direita e organizados por militares agiam, desde a segunda metade dos anos 1980, imbuídos de uma ideologia anticomunista e autoritária, e de um sentimento saudosista em relação ao regime militar - período no qual os militares, enquanto instituição, tinham status elevado e acesso direto aos recursos do Estado brasileiro (SANTOS, 2009).

Mas não é só de extremistas que se compõe a direita brasileira. Mais moderados, comparativamente, os conservadores têm protagonizado a história 


\section{HISTÓRIA \\ POR UMA HISTÓRIA DAS DIREITAS}

Fabrício Ferreira de Medeiros

política republicana, interferindo nos rumos das políticas públicas e na conformação de determinadas tendências de opinião. Atuam no nível partidário e no seio da sociedade civil, principalmente por meio de denominações religiosas e movimentos sociais. A exemplo disto, cito o Movimento Escola Sem Partido (MESP), o qual vem sendo investigado exaustivamente pelo professor Fernando Penna.

Criado em 2004 pelo advogado Miguel Nagib, o MESP surgiu como uma iniciativa voltada para o combate daquilo que considera a "contaminação políticoideológica das escolas brasileiras, em todos os níveis: do ensino básico ao superior" e "a instrumentalização do ensino para fins políticos, ideológicos e partidários". ${ }^{4}$ Neste sentido, o coordenador do Movimento, Miguel Nagib, sugere que o sistema escolar brasileiro estaria sendo alvo de uma doutrinação constante por parte dos professores, frente a uma "audiência cativa", tal como o advogado chama os estudantes. O MESP, porém, não parou por aí. As denúncias de doutrinação já ganharam espaço em diversas casas legislativas, inclusive na Câmara dos Deputados e no Senado Federal.

A sensibilização de políticos e setores civis para tais ideias, por outro lado, suscitou críticas, inclusive de muitos professores, a exemplo de Penna. Participando de audiências públicas, programas de TV, entrevistas, seminários e através da publicação de artigos, o professor dr. em Educação tem evidenciado que, longe de buscar o fomento ao debate nas escolas, o que o MESP vem fazendo é tentar reduzir o magistério e a educação à categoria de instrução, na qual os conteúdos escolares ficam isolados dos valores, princípios e experiências de vida dos estudantes. $\mathrm{Na}$ concepção de Nagib e do MESP, professor não educa, apenas instrui. Quem educa são os pais e as famílias, isso porque o professor não poderia ensinar valores distintos daqueles professados pelos pais dos estudantes. Mostrando um alto grau de desconhecimento (ou má fé em relação à) da legislação educacional, o dito Movimento tem procurado cercear o debate nas salas de aula, disparando ataques constantes contra os docentes e sua autonomia profissional. De todo modo, Penna já explicitou que, a despeito do caráter aparentemente antipartidário e democrático do MESP, seus discursos são construídos, em boa medida, com base no anticomunismo,

\footnotetext{
${ }^{4}$ Disponível em: http://www.escolasempartido.org/. Acesso em: 14 de maio de 2018.
} 


\section{HISTÓRIA \\ POR UMA HISTÓRIA DAS DIREITAS}

Fabrício Ferreira de Medeiros

no conservadorismo, na homofobia, no racismo (PENNA, 2017) e no ódio promovido contra os professores (PENNA, 2016). Em suas denúncias, a esquerda brasileira, em particular o Partido dos Trabalhadores (PT), tem sido apontada como a principal agente promotora da doutrinação imputada ao meio escolar. Assim, o MESP se define como um Movimento de oposição às esquerdas, a exemplo de outros movimentos, partidos e grupos direitistas.

A dimensão partidária foi analisada por Karolina Roeder (2016), dentre outros autores. Para a cientista política, os partidos políticos situados no campo das direitas, no Brasil, podem ser reunidos em três subcampos, a saber: 1) a "nova direita", subdividida entre uma ala neoconservadora, adepta de uma "intervenção estatal limitada e conservadora moral"; e uma corrente neoliberal, "com partidos orientados pelo mercado, defensores da mínima intervenção estatal na economia", e progressista em termos morais e comportamentais; 2) a "velha direita" (também chamada de "direita tradicional"), afinada com o neoliberalismo, mas conservadora no campo moral e social; e, por fim, 3) os "partidos fisiológicos, que não apresentam posicionamentos programáticos firmes sobre nenhum dos temas analisados (neoliberalismo e conservadorismo)". Em termos eleitorais, segundo Roeder, examinando os resultados das eleições para a Câmara dos Deputados (1998 a 2014), observa-se um aumento significativo "de candidatos e eleitos pelos partidos fisiológicos e da nova direita", em detrimento "das candidaturas e eleitos pelos partidos da velha direita, no mesmo período" (ROEDER, 2016, p. 3). Em termos sociais, a autora argumentou que a "nova direita" se apresenta distinta em relação à velha direita e aos partidos fisiológicos, na medida em que agrupa comunicadores e líderes religiosos. Suas bases eleitorais estariam "alicerçadas em um eleitorado conservador de base neopentecostal e preocupados com seus direitos de consumidores" (ROEDER, 2016, p. 22).

No campo conservador, diversos estudos têm focado na atuação evangélica, sobretudo a nível partidário. Há trabalhos que situam a ascensão evangélica no campo político-partidário como expressão de uma reação engajada contra determinadas pautas que dizem respeito às mulheres, de modo geral, e à comunidade LGBT, quais sejam: a legalização do aborto, o reconhecimento da união homoafetiva estável (casamento) (VILLAZÓN, 2015), mas também a criminalização da homofobia 


\section{HISTÓRIA \\ POR UMA HISTÓRIA DAS DIREITAS}

Fabrício Ferreira de Medeiros

e a comercialização da pílula do dia seguinte (MAIA, 2006). Segundo o historiador Jonas Koren (2016), os evangélicos estão se destacando no cenário político brasileiro, ao defender determinada concepção de família (heterossexual), contra a ampliação do modelo familiar, isto é, no que concerne ao reconhecimento legal de famílias homoafetivas e a descriminalização do aborto. A criminalização da homofobia, por exemplo, vem sendo combatida entre os evangélicos, sob a justificativa de que estaria cerceando-se, desta maneira, a liberdade de crença e expressão, proibindo-se as pessoas de desaprovar a homossexualidade. Para certas lideranças evangélicas, como o pastor Silas Malafaia, a tentativa de criminalizar a homofobia equivaleria a uma inversão de lógica, quando os opositores a homossexualidade passam a sofrer o preconceito (KOREN, 2016).

A luta contra o avanço das agendas do aborto e LGBT, além disto, converge para o fortalecimento da oposição a partidos de esquerda e ao PT, principalmente, isto porque sob seus governos (Lula da Silva, 2003-2010 e Dilma Rousseff, 20112016), tanto a regulamentação do aborto quanto as questões de interesse da comunidade LGBT ganharam vulto no Legislativo. De acordo com Koren, Malafaia foi um dos expoentes do protagonismo político-evangélico, associando o PT, os movimentos LGBT e o avanço da pauta pró-aborto ao comunismo, sobretudo a partir da eleição presidencial de 2010, quando o pastor "[...] passou a adotar posições críticas em relação ao PT e aos governos encabeçados por este partido" (KOREN, 2016, p. 94). Neste mesmo ponto, Janine Trevisan (2015) argumentou que a atuação evangélica combinou o antipetismo, o anticomunismo e a oposição a LGBT, pois deputados(as) petistas tenderam a favorecer a apresentação e aprovação de Projetos de Lei (PL) no sentido da descriminalização do aborto, da legalização da união homoafetiva e da criminalização da homofobia. A dita oposição também se daria porque, na visão de várias lideranças evangélicas, a aprovação dos respectivos PL, sob governos esquerdistas, seria prejudicial à liberdade religiosa. Desse modo, os evangélicos, aos poucos, passaram a definir seus posicionamentos políticos em oposição às esquerdas e ao avanço da ampliação de certos direitos civis, vistos por estes segmentos como prejudiciais a sua crença e ao povo brasileiro como um todo. 


\section{HISTÓRIA \\ POR UMA HISTÓRIA DAS DIREITAS}

Fabrício Ferreira de Medeiros

Seja como for, a "nova direita" também apresenta uma corrente neoliberal, progressista em termos comportamentais, mas, diferentemente dos conservadores, nitidamente crítica ao estatismo. Segundo Ricardo Mendes, as novas direitas retomam alguns discursos e valores caros às "velhas direitas" dos anos 1960. O historiador citou como exemplo, neste caso, o Instituto Millenium, o qual, atuando como think tank, vem divulgando no Brasil o pensamento neoliberal e determinada concepção de democracia. Nas palavras do historiador,

O Instituto, afirma possuir como elemento central uma preocupação com o debate e a defesa da democracia. No entanto, o sistema democrático segundo o Instituto, se restringe a um tipo específico: associado à propriedade privada, à livre iniciativa, à existência de um Estado mínimo e à proposição de um sistema marcado por uma democracia representativa que se oporia ao que denominam por 'democracia direta'.

[...] Nesse sentido, democracia para os membros do Instituto significa economia de mercado, propriedade privada e livre iniciativa. Qualquer projeto político que se apresente atacando esses princípios são rotulados de antidemocráticos. [...] São argumentos que retomam em grande medida o projeto político de boa parte dos articuladores de 1964 (MENDES, 2014, p. 159).

A democracia, para o Instituto Millenium (mas também na perspectiva de outros think tanks e grupos midiáticos), deveria ser situada no campo do liberalismo econômico. O Estado, portanto, não poderia ampliar e aprofundar sua intervenção na sociedade e na economia além de um mínimo necessário. Nesta perspectiva, a democracia é interpretada como um regime de poder assentado na garantia da liberdade individual frente ao poder coercitivo do poder público. No entanto, a participação política e a própria qualidade da representação política são tidas como questões menores. Com base nas reflexões de Nadia Urbinati a respeito da representação democrática, é possível argumentar que a direita neoliberal defende uma concepção de democracia essencialmente eleitoral, mas pouco representativa. Esta corrente teórica do governo representativo preconiza uma combinação entre:

[...] elitismo nas instituições políticas (o único local tanto da deliberação bem como do voto) e legitimação popular (localizada 


\section{HISTÓRIA \\ POR UMA HISTÓRIA DAS DIREITAS}

Fabrício Ferreira de Medeiros

na votação através da eleição), na qual o primeiro consistiria no domínio da competência e a última no domínio do consentimento (URBINATI, 2006, p. 192).

Afirma-se, neste modelo, uma separação profunda de funções e autoridade entre governantes e governados, representantes e representados. O consentimento é alçado à base do político, porém, sob uma condição de passividade e não de participação, o que diminui ou ao menos marginaliza a questão da responsabilização dos atos e ações dos ocupantes do poder público. Os cidadãos são chamados a participar, mas tal participação, para as direitas, deve ser circunscrita a determinadas conjunturas ou mesmo a episódios, não se revertendo em fenômeno contínuo.

Este caráter da direita neoliberal foi, inclusive, ressaltado por Demian Melo (2016). Para o historiador, quer na conjuntura de 1964, quer nos anos 1990, período em que os governos Collor de Mello (1990-1992) e Fernando Henrique Cardoso (1995-2002) implementaram e aprofundaram, respectivamente, a agenda neoliberal no país, o que ficou evidente foi que a direita brasileira adotou estratégias "fundamentalmente antimobilizadoras" (MELO, 2016, p. 67). Sobretudo na década de 1990, segundo o autor, a atuação da direita neoliberal foi pautada não pelo incentivo à participação de segmentos majoritários da sociedade, mas sim pelo consenso passivo (MELO, 2016). Conquistado o objetivo estratégico, nestes casos, a eleição de representantes (neo)liberais para a Presidência da República, logo os cidadãos seriam incitados a se desmobilizarem, voltando ao posto de cidadãos passivos.

A desmobilização popular, portanto, fundamenta uma visão elitista e direitista da democracia, em geral, mais afinada com o inigualitarismo do que, propriamente, com o igualitarismo defendido entre as esquerdas (ARAUJO, 2004). De qualquer maneira, as direitas não se utilizam, em absoluto, dos mesmos discursos ou das mesmas estratégias de ação política. Em alguns casos, atuam no campo institucional e/ou partidário, buscando interferir diretamente na formulação de políticas públicas. Em outros, adotam a via dos movimentos sociais, buscando sensibilizar o maior número possível de pessoas para as suas pautas, valores e/ou projetos políticos. Ainda na sociedade civil, existem os think tanks e os grupos midiáticos, os quais, particularmente no contexto brasileiro da Nova República, engajam-se na construção 


\section{HISTÓRIA \\ POR UMA HISTÓRIA DAS DIREITAS}

Fabrício Ferreira de Medeiros

de um consenso neoliberal, expresso na defesa: da intervenção do Estado na economia, da iniciativa e da propriedade privadas, da privatização e diminuição do tamanho do Estado brasileiro, da resolução dos conflitos trabalhistas em benefício do capital, etc.

O estudo sobre as direitas, como é possível perceber, não se resume à esfera partidária e política stricto sensu. Aliás, James Bowen (2011) já havia ressaltado a necessidade de se romper com a ênfase nos partidos políticos, considerando-se a atuação das direitas ao nível da sociedade civil, sem deixar de perceber suas articulações com outras arenas e as instituições políticas. Movimentos direitistas, como o MESP, buscam articulações com lideranças políticas, obtendo o apoio de vários parlamentares (particularmente dos evangélicos), os quais se comprometem com a apresentação e aprovação de PL fundamentados no Movimento, chamados de Projeto Escola Sem Partido. Grupos militares, especialmente em seus endereços eletrônicos, não raro, reproduzem artigos escritos por expoentes da direita, a exemplo de Olavo de Carvalho. Afinadas no anticomunismo, as direitas nacionalista-ditatorial e conservadora têm se posicionado sistematicamente contra os governos petistas, denunciando supostos planos de comunização do Brasil. Em suas batalhas, aproveitam materiais produzidos por suas congêneres direitistas, sob o compromisso comum de derrotar o PT. Em alguns casos, aliás, a intransigência das direitas se expressa na apresentação de PL direcionados a criminalização do comunismo, ${ }^{5}$ fato que evidencia o viés antidemocrático e autoritário de alguns atores situados no campo oposto às esquerdas.

Mas as articulações não se realizam apenas no âmbito nacional. As conexões entre as direitas também assumem dimensão transnacional, a exemplo do que ocorreu na conjuntura de 1964, quando o complexo IPES-IBAD-ESG, atuando contra as esquerdas, em geral, e o governo João Goulart, em particular, somou forças com grupos estrangeiros e, ao menos no caso do IPES, comprovou-se o recebimento de

\footnotetext{
${ }^{5}$ Refiro-me ao PL 5358/2016, de autoria do deputado federal Eduardo Bolsonaro, do Partido Social Cristão de São Paulo.

Disponível em: http://www.camara.gov.br/proposicoesWeb/fichadetramitacao?idProposicao=2085411. Acesso em: 14 de maio de 2018.
} 


\section{HISTÓRIA \\ POR UMA HISTÓRIA DAS DIREITAS}

Fabrício Ferreira de Medeiros

"contribuições financeiras estrangeiras para campanhas eleitorais, o que a lei proibia" (DREIFUSS, 1984 apud HOEVELER, 2016, p. 82). Além disto, o apoio externo às direitas brasileiras realizou-se mediante a oferta de "cursos de formação sindical pelega para operários até viagens de intercâmbio de estudantes para os Estados Unidos, programa que visava explicitamente à absorção, por aqueles, dos valores da livre iniciativa e do livre mercado" (DREIFUSS, 1987 apud HOEVELER, 2016, p. 82).

Recentemente, segundo Rejane Hoeveler, observou-se a influência significativa do Atlas Network, um think tank dos Estados Unidos da América, sobre algumas direitas brasileiras atuantes na crise política do governo Dilma, a exemplo do Movimento Brasil Livre. Valendo-se do neoliberalismo como ideologia política, "o Atlas Network atua basicamente como fomentador, financeiro e intelectual, de entidades que têm como princípio a defesa de 'políticas públicas orientadas para o mercado'. Ajudam mais de 400 think tanks em mais de oitenta países [...]', dentre eles o Brasil, "[...] um dos países que latino-americanos que mais recebem recursos, cerca de 20 mil dólares anuais [...]" (HOEVELER, 2016, p. 87 e 88).

Neste sentido, é necessário estudar com maior profundidade as articulações e as formas de atuação das direitas. Em relação ao cenário brasileiro, ainda são tímidas as pesquisas voltadas para as direitas em uma perspectiva comparada. ${ }^{6}$ Em geral, sobressaem os estudos sobre partidos políticos. Mas as articulações civis entre as direitas conservadora e neoliberal, por exemplo, carecem de análises suficientemente assentadas na empiria. Há lacunas sobre vários temas, como as formas de obtenção de recursos financeiros, as plataformas de atuação, as alianças entre civis, políticos e mesmo militares, etc. Sobre estes últimos, aliás, existem pouquíssimas pesquisas, dentre as quais, a dissertação de Santos (2009) talvez seja o melhor exemplar.

\section{Considerações finais}

\footnotetext{
${ }^{6}$ A única pesquisa que conheço, com base nesta abordagem, foi produzida por Mendes (2003), na qual o historiador comparou as direitas organizadas nos meios: civil, político e militar.
} 


\section{HISTÓRIA \\ POR UMA HISTÓRIA DAS DIREITAS}

Fabrício Ferreira de Medeiros

Neste artigo, busquei identificar algumas características das direitas e discutir a validade deste conceito como ferramenta analítica no contexto brasileiro. Apresentando-se de maneira plural, tanto em termos de filiação ideológica (neoliberal, conservadora, nacionalista-ditatorial, neofascista, etc.) quanto ao nível de atuação (vias: partidária, midiática, movimentos sociais, religiosa), as direitas têm atuado como protagonistas na história política brasileira, em especial, na Nova República. Visitando estudos focados nas dimensões latino-americana e brasileira, tentei construir um mapa da historiografia das direitas, ainda que pequeno e seletivo, buscando rever aspectos conceituais e apresentar direções de pesquisa para os investigadores interessados nesta temática.

Apesar do crescimento do número de pesquisas, percebo que ainda existem lacunas e questões apenas tangenciadas pelos estudiosos do tema. As articulações entre as direitas, a nível regional, nacional e transnacional, aguardam estudos mais atentos ao material empírico disponível. Suas bases de atuação: midiática, movimentos sociais, partidária, religiosa, por outro lado, ainda carecem de pesquisas comparativas. A maior parte dos estudos comparativos sobre as direitas se situa na dimensão político-partidária, com destaque para trabalhos oriundos da Ciência Política. Porém, dificilmente se extrapola este nível de análise, buscando-se apontar as conexões civis das direitas partidárias. No máximo, deslumbra-se o estudo sobre o perfil social do eleitorado direitista. Por outro lado, a direita nacionalista-ditatorial quase não recebeu atenção entre os pesquisadores. Devido à importância dos militares na história republicana e ao saudosismo que muitos civis possuem em relação aos tempos de regime militar, seria interessante que fossem produzidos mais estudos sobre esta temática, buscando-se compreender as raízes ideológicas dos grupos formados por militares, bem como suas percepções sobre a qualidade da democracia brasileira, da representação política e as políticas públicas, etc.

Argumento que o estudo das direitas é fundamental para a compreensão dos processos e problemas políticos contemporâneos no Brasil. O consenso neoliberal da década de 1990 não pode ser examinado sem que se faça menção à atuação da direita reunida na grande imprensa do eixo Rio-São Paulo (O Globo, O Estado de $S$. Paulo, Folha de S. Paulo, em especial), a qual se comprometeu, ao longo de todo o 


\section{HISTÓRIA \\ POR UMA HISTÓRIA DAS DIREITAS}

Fabrício Ferreira de Medeiros

período mencionado, a sensibilizar tendências da opinião pública para a necessidade de execução de reformas pró-mercado, em detrimento da capacidade de intervenção do Estado na economia e do combate às desigualdades socioeconômicas. Também não é possível compreender a crise do governo Dilma (2014-2016) sem atentar para a deterioração de sua base social e para a dinâmica dos protestos à direita, os quais exigiram sistematicamente seu impeachment, a partir de 2015.

No plano partidário, como já foi mencionado neste artigo, a atuação política dos evangélicos contra o avanço da descriminalização do aborto e da agenda LGBT destacou-se, demonstrando as dificuldades enfrentadas pelos parlamentares na aprovação de Projetos que poderiam ampliar uma série de direitos civis e subsidiar o combate à homofobia.

Além disto, as direitas, principalmente alguns setores da classe média, têm demonstrado um comportamento intransigente no que diz respeito ao ingresso de estudantes pobres nas Instituições de Ensino Superior, como também à presença das camadas menos abastadas em espaços até pouco tempo dominados pelas classes médias, como shoppings centers e aeroportos. Segundo Sávio Cavalcante (2015), o sucesso na execução de determinadas políticas públicas de transferência da renda (como o Programa Bolsa Família) e o ingresso no Ensino Superior (através cotas, por exemplo) atingiram a ideologia meritocrática da classe média brasileira. Ao definir outros parâmetros de mobilidade social, para além do esforço individual, os governos petistas teriam secundarizado o "[...] critério meritocrático como forma de escolha/seleção em instituições ou serviços públicos" (CAVALCANTE, 2015, p. 180), permitindo que se fortalecesse uma oposição direitista contra o governo Dilma.

De qualquer maneira, é necessário estudar com maior profundidade estes temas. Não podemos nos debruçar sobre as direitas sem explicitar, desde logo, o entendimento que possuímos do conceito de "direita". Não é satisfatório usar este termo como mera ferramenta de acusação de adversários políticos, em tom pejorativo. A direita não pode ser vista como xingamento, mas sim na condição de chave analítica para o entendimento de problemas e processos característicos do espaço político (e por que não, social e cultural?) de determinada sociedade, em certo período histórico. Assim, defendo que o estudo das direitas não só é possível, como é fundamental em 


\section{HISTÓRIA \\ POR UMA HISTÓRIA DAS DIREITAS}

Fabrício Ferreira de Medeiros

qualquer tentativa de interpretação da história política republicana, em particular, no período recente.

\section{Referências}

ARAUJO, Octavio R. Derechas y ultraderechas en el mundo. México, D.F.: Siglo XXI Ed., 2004.

BARBOSA, Jefferson R. Skinheads chauvinistas: integralistas, os "carecas do subúrbio" e o nacional-socialismo brasileiro. In: PATSCHIKI, Marcos A. S.; (orgs.). Tempos conservadores: estudos críticos sobre as direitas. Goiânia: Edições Gárgula, 2016. p. 77-96.

BOBBIO, Norberto. Direita e esquerda: razões e significados de uma distinção política. Tradução Marco Aurélio Nogueira. São Paulo: Editora UNESP, 1995. [1994].

BORON, Atilio A. ¿Qué debemos entender por "derecha”? In: PALAU, Marielle (coord.). La ofensiva de las derechas en el Cono Sur. Assunção: Base IS, 2010. p. 13-20.

BOWEN, James David. The Right in "New Left" Latin America. Journal of Politics in Latin America, v. 3, n. 1, p. 99-124, 2011.

CAVALCANTE, Sávio. Classe média e conservadorismo liberal. In: VELASCO E CRUZ, S.; KAYSEL, A.; CODAS, G. (orgs.). Direita, volver!: o retorno da direita e o ciclo político brasileiro. São Paulo: Editora Fundação Perseu Abramo, 2015. p. 177196.

CODATO, Adriano; BOLOGNESI, Bruno; ROEDER, K. M. A nova direita brasileira: uma análise da dinâmica partidária e eleitoral do campo conservador. In: VELASCO E CRUZ, S.; KAYSEL, A.; CODAS, G. (orgs.). Direita, volver!: o retorno da direita e o ciclo político brasileiro. São Paulo: Editora Fundação Perseu Abramo, 2015. p. 115-144.

FONTES, V. Velhas e remodeladas formas da direita no Brasil. In: PALAU, Marielle (coord.). La ofensiva de las derechas en el Cono Sur. Assunção: Base IS, 2010. p. 77-88.

GIORDANO, Verónica. ¿Qué hay de nuevo en las "nuevas derechas"? Nueva Sociedad, Buenos Aires, n. 254, p. 46-56, nov.-dez. 2014.

HINKELAMMERT, Franz J. Democracia y nueva derecha en América Latina. Nueva Sociedad, Buenos Aires, n. 98, p. 104-115, nov.-dez. 1988.

HOEVELER, Rejane. A direita transnacional em perspectiva histórica: o sentido da "nova direita" brasileira. In: DEMIER, Felipe; HOEVELER, Rejane (orgs.). A onda 


\section{HISTÓRIA \\ POR UMA HISTÓRIA DAS DIREITAS}

Fabrício Ferreira de Medeiros

conservadora: ensaios sobre os atuais tempos sombrios no Brasil. Rio de Janeiro: Mauad, 2016. p. 77-92.

JIMÉNEZ, Edgar. La nueva derecha: Dilema de la política latinoamerica. Realidad, San Salvador, n. 5, p. 401-412, sep.-oct. 1988.

KONDER, Leandro. Unidade da direita, Jornal da República, São Paulo, 20 de set. de 1979 , p. 4.

KOREN, Jonas C. Ministério Silas Malafaia: evangelizando à direita (2000-2013). Dissertação (Mestrado em História), Programa de Pós-Graduação em História, Universidade Estadual do Oeste do Paraná (PPGH-UNIOESTE), Marechal Cândido Rondon, 2016.

MAIA, Eduardo L. C. Religião e Política: o fenômeno evangélico. Dissertação (Mestrado em Sociologia Política), Programa de Pós-Graduação em Sociologia Política, Universidade Federal de Santa Catarina (PPGSP-UFSC), Florianópolis, 2006.

MELO, Demian. A direita ganha as ruas: elementos para um estudo das raízes ideológicas da direita brasileira. In: DEMIER, Felipe; HOEVELER, Rejane (orgs.). A onda conservadora: ensaios sobre os atuais tempos sombrios no Brasil. Rio de Janeiro: Mauad, 2016. p. 67-76.

MENDES, R. A. S. Novas direitas e velhos discursos? In: SCHUSTER, Karl [et al.]. Velhas e novas direitas: a atualidade de uma polêmica. Recife EDUPE, Editora da Universidade de Pernambuco, 2014. p. 148-160.

Visões das direitas no Brasil (1961-1965). Tese (Doutorado em História Moderna e Contemporânea), Programa de Pós-Graduação em História, Universidade Federal Fluminense (PPGH-UFF), Niterói, 2003.

PENNA, F. A. O Escola sem Partido como chave de leitura do fenômeno educacional. In: FRIGOTO, Gaudêncio (org.). Escola "sem" partido: esfinge que ameaça a educação e a sociedade brasileira. Rio de Janeiro: UERJ, LPP, 2017. p. $35-48$.

. O ódio aos professores. In: AÇÃO EDUCATIVA ASSESSORIA, PESQUISA E INFORMAÇÃO (org.). A ideologia do movimento Escola Sem

Partido: 20 autores desmontam o discurso. São Paulo: Ação Educativa, 2016. p. 93100.

ROCHA, Camila. Direitas em rede: think tanks de direita na América Latina. In: VELASCO E CRUZ, S.; KAYSEL, A.; CODAS, G. (orgs.). Direita, volver!: o retorno da direita e o ciclo político brasileiro. São Paulo: Editora Fundação Perseu Abramo, 2015. p. 261-278.

ROEDER, K. M. Existe uma nova direita no Brasil? Uma proposta de classificação e análise de seu perfil social. Anais do X Encontro da Associação Brasileira de Ciência Política, Belo Horizonte, 2016. 


\section{HISTÓRIA \\ POR UMA HISTÓRIA DAS DIREITAS}

Fabrício Ferreira de Medeiros

ROMERO, Jose L. El pensamiento político de la derecha latinoamericana. Buenos Aires: Paidos, 1970.

SANTOS, E. H. J. Extrema Direita, volver! - Memória, ideologia e política dos grupos formados por civis e a reserva militar. Dissertação (Mestrado em Ciência Política), Programa de Pós-Graduação em Ciência Política, Universidade Federal Fluminense (PPGCP-UFF), Niterói, 2009.

TREVISAN, J. B. A atuação política pentecostal em confronto com o movimento LGBT no Brasil redemocratizado. Tese (Doutorado em Ciências Sociais), Programa de Pós-Graduação em Ciências Sociais, Pontifícia Universidade Católica do Rio Grande do Sul (PPGCS-PUC-RS), Porto Alegre, 2015.

URBINATI, Nadia. O que torna a representação democrática? Lua Nova, São Paulo, n. 67, p. 191-228, 2006.

VILLAZÓN, J. C. Velhas e novas direitas religiosas na América Latina: os evangélicos como fator político. In: VELASCO E CRUZ, S.; KAYSEL, A.; CODAS, G. (orgs.). Direita, volver!: o retorno da direita e o ciclo político brasileiro. São Paulo: Editora Fundação Perseu Abramo, 2015. p. 163-175.

Artigo recebido em 14/05/2018 Artigo aceito em 05/01/2019 